Original Scientific Article

\title{
VARIABILITY OF STRESS INDICATORS IN JUMPING HORSES IN PARKOUR DUE TO HORSE AGE AND COMPETITIVE SEASON
}

\author{
Maja Gregić $^{1}$, Tina Bobić ${ }^{1}$, Mirjana Baban ${ }^{1}$, Gjoko Bunevski², Vesna Gantner ${ }^{1}$ \\ ${ }^{1}$ Department for Animal Production and Biotechnology, Faculty of Agrobiotechnology \\ Osijek, University of Josip Juraj Strossmayer in Osijek, Vladimira Preloga 1, \\ 31000 Osijek, Croatia \\ ${ }^{2}$ Faculty of Agricultural Sciences and Food, Ss. Cyril and Methodius University of Skopje, \\ Skopje, Republic of Macedonia
}

Received 15 June 2019; Received in revised form 20 July 2020; Accepted 31 July 2020

\begin{abstract}
Aiming to determine the variability in stress indicators due to horse age and competitive season (May, July, September) in jumping horses in parkour, research was performed on 14 studs (7 younger, and 7 older) trained and bred in the same conditions. The stress indicators (heartbeats, cortisol, glucose, and lactate concentrations in saliva) were measured or sampled before, during and at the end of the training - parkour jumping. The significance of the differences in stress indicators between the horse age classes regarding the competitive season was tested by Tukey's test. Based on determined results it could be concluded that all stress indicators, during the entire competitive season, were higher in younger (less experienced) than in older (more experienced) horses. Furthermore, all stress indicators, with the exception of heartbeats, were highest in the peak of competitive season (July), while the lowest values of all stress indicators were determined at the end of competitive season (September). Monitoring of stress indicators, especially heartbeats, could be used for routine evaluation of horse preparedness for a particular activity.
\end{abstract}

Key words: jumping horses, parkour, stress indicators

\section{INTRODUCTION}

Equestrian sport represents an Olympic discipline under the Fédération Equestre Internationale - FEI. In order to achieve the results in equestrian sports, an adequate horse and good training are required. Horse training implies achieving concentration and fitness for a certain type of equestrian sport with special emphasis on preservation of health, psychological and physical condition as well as longevity of the horse (1). Hick and Hick (2) defined training as a constant repetition

Corresponding author: Dr. Maja Gregić, PhD

E-mail address: msakac@fazos.hr

Present address: Department for Animal Production and Biotechnology,

Faculty of Agrobiotechnology Osijek, University of Josip Juraj

Strossmayer in Osijek, Vladimira Preloga 1, 31000 Osijek, Croatia Phone: +385 31554 860; Fax: +38531554853

Copyright: (C) 2020 Gregić M. This is an open-access article published under the terms of the Creative Commons Attribution License which permits unrestricted use, distribution, and reproduction in any medium, provided the original author and source are credited.

Competing Interests: The authors have declared that no competing interests exist.

Available Online First: 16 September 2020

Published on: 15 October 2020

https://doi.org/10.2478/macvetrev-2020-0029 of physical and mental actions to encourage the development of adjustments to those actions, which would lead to the efficiency increase in the same actions. Equestrian sports are physically very demanding; therefore, it could induce stress in horses (3). A desirable characteristic of a horse used in show jumping sports is the one with great tolerance to stress and quick adaptation. Stress in horses can be evaluated by observing and analysis of the physiology and the concentrations of certain substances in the organism (4) as well.

According to König et al. (5) the cardiovascular parameters (heartbeats/minute), cortisol, eye temperature and behaviour are good indicators of short-term stress. The heartbeats can vary from 50 to 240 heartbeats per minute depending on movements (step or severe effort) and horses' age (6). The salivary cortisol, a widely used measure to evaluate stress response in horses (7) is affected by the time of day and season, as well as body condition score. Furthermore, the concentration of glucose and lactate in saliva could show the 
body resistance to the physical stress or training effect (8). The salivary cortisol test seems to be a useful and efficient method to evaluate the horses (9). A variety of factors affect the concentration of glucose and lactate in saliva, such as fitness, age, sex, breeding conditions, and equestrian sport discipline. The aim of this research was to determine the variability in stress indicators (heartbeats, cortisol, glucose, and lactate concentration in saliva) in relation to age (younger and older) and competitive season (May, July, September) in jumping horses in parkour.

\section{MATERIAL AND METHODS}

The research was performed on Holstein and Croatian studs used in jumping horse sports, trained and bred in the same conditions. Croatian sport horse has been bred since the 1970s in the Republic of Croatia. The breeding goal is achieving a noble, beautiful, regular, versatile warm-blooded horse that has long, fast and energetic movements, strong momentum and thrust, and is of good character and suitable for use in all equestrian sports. All horses were healthy and accommodated in the same conditions, in separate stalls. Feeding was generally in the same regiments with a small variation between winter and summer season. One person was responsible for monitoring the sport and fitness conditions in horses. During the winter period, the horses regularly spent 20 minutes daily on a running track, lunging and periodically with a saddle, while during the preparatory and competitive period, the training included a running track, lunging, work under the saddle and show jumping, as well as independent motoric movements in an outlet. According to age, horses were divided in two groups of seven animals: younger (4 to 5 years old) and older (8 to 9 years old).

Furthermore, the research was performed during the competitive season in May, July, and September. The stress indicators (heartbeats, cortisol, glucose, and lactate) were measured or sampled before, during, and at the end of the training - parkour jumping $(3,10)$. During the training, each horse jumped in an equally set parkour with eight obstacles $80-90 \mathrm{~cm}$ high with a dry sand ground. The equipment of the jumping horses was individual, adapted to each horse and the saddle pad was always made of cotton. For the measurements of heartbeats polar equipment (RS800CX N G3), equine electrode set for $\mathrm{H} 2$ sensor, and equine health check FT1 were used.

Saliva samples in horses were taken by cotton swabs (Salivette Cortisol, code blue) fixed by the paean, inserted in the oral cavity, withdrawn after one minute, and stored adequately. Saliva swabs were processed in the laboratory and were stored at $-20^{\circ} \mathrm{C}$ until the analysis.

The cortisol concentration in the saliva was determined by ELISA 96 tests (DES6611). The lactate concentration in saliva was determined according to the Lactate Photometry Method on a biochemical analyzer (Beckman Coulter AU400, Japan). Furthermore, the glucose concentration in saliva was performed by Enzymatic Method at the same biochemical analyzer. Basic variability of measured stress indicators in jumping horses during the training in parkour is presented in Table 1.

SAS/STAT version 9.4 (SAS Institute Inc., 2002) was used for the statistics analysis. The significance of the differences in stress indicators (heartbeats, cortisol, glucose, and lactate) between the horse age classes (younger and older in relation to the competitive season (May, July, September) was tested by Tukey's test (PROC GLM, MEANS statement) using the following model:

$$
y_{i j}=\mu+A_{i}+e_{i j}
$$

where $\mathrm{y}_{\mathrm{ij}}=$ estimated trait

$\mu=$ intercept

$A_{j}=$ fixed effect of age $j(j=$ younger / older $)$

$\mathrm{e}_{\mathrm{ij}}=$ residual

Table 1. Basic statistical parameters of stress indicators in jumping horses in parkour

\begin{tabular}{lccccc}
\hline Stress indicators & Mean & SD & CV & MIN & MAX \\
\hline Heartbeats/min & 67.23 & 46.55 & 69.23 & 25.00 & 256.00 \\
Cortisol (ng/ml) & 1.22 & 0.87 & 73.60 & 0.03 & 4.75 \\
Glucose (mg/dl) & 47.51 & 58.92 & 123.91 & 0.27 & 361.92 \\
Lactate (mmol/l) & 1.02 & 0.59 & 61.46 & 0.08 & 3.37 \\
\hline
\end{tabular}


Table 2. Means of stress indicators in jumping horses in relation to age in competitive season - May

\begin{tabular}{lcccc}
\hline Stress indicators/age & Heartbeats/min & $\begin{array}{c}\text { Cortisol } \\
(\mathbf{n g} / \mathbf{m l})\end{array}$ & $\begin{array}{c}\text { Glucose } \\
(\mathbf{m g} / \mathbf{d l})\end{array}$ & $\begin{array}{c}\text { Lactate } \\
(\mathbf{m m o l} / \mathbf{l})\end{array}$ \\
\hline Younger & $75.242 \pm 51.049^{\mathrm{A}}$ & $1.363 \pm 1.002^{\mathrm{A}}$ & $56.821 \pm 49.645^{\mathrm{A}}$ & $1.237 \pm 0.696^{\mathrm{A}}$ \\
Older & $63.670 \pm 41.450^{\mathrm{A}}$ & $0.966 \pm 0.635^{\mathrm{B}}$ & $34.868 \pm 28.308^{\mathrm{B}}$ & $0.738 \pm 0.473^{\mathrm{B}}$ \\
\hline
\end{tabular}

Means marked with different letters $(A, B)$ differ statistically highly significant $(\mathrm{p}<0.001)$

\section{RESULTS}

Means of the stress indicators (heartbeats, cortisol, glucose, and lactate concentrations) in relation to the horse age classes (younger, and older) and to the competitive season (May, July, September) are shown in Tables $2-4$. All measured stress indicators during the competitive season (May) were significantly higher in younger horses $(\mathrm{p}<0.001)$ with higher concentrations of cortisol, glucose, and lactate. The difference in heartbeats was higher in younger horses (diff $=11.572$ heartbeats $/ \mathrm{min}$ ) but was not statistically significant $(\mathrm{p}>0.05)$.
During the competitive season (July), significantly $(p<0.001)$ higher concentrations of cortisol and lactate were determined in younger horses, while the difference in glucose concentration was not statistically significant $(\mathrm{p}>0.5)$. Also, young horses had significantly $(p<0.001)$ higher heartbeats. Furthermore, determined concentrations of cortisol, glucose and lactate were highest in July, implicating the highest stress level in the peak of the competitive season.

During the competitive season (September), significantly $(p<0.001)$ higher values of all analyzed stress indicators were determined in younger horses. The lowest values of all stress indicators were measured in September, for all horses, regardless of age.

Table 3. Means of stress indicators in jumping horses in relation to the age in competitive season - July

\begin{tabular}{lcccc}
\hline Stress indicators/age & Heartbeats/min & $\begin{array}{c}\text { Cortisol } \\
(\mathbf{n g} / \mathbf{m l})\end{array}$ & $\begin{array}{c}\text { Glucose } \\
(\mathbf{m g} / \mathbf{d l})\end{array}$ & $\begin{array}{c}\text { Lactate } \\
(\mathbf{m m o l} / \mathbf{l})\end{array}$ \\
\hline Younger & $74.802 \pm 55.943^{\mathrm{A}}$ & $1.559 \pm 0.995^{\mathrm{A}}$ & $62.610 \pm 54.483^{\mathrm{A}}$ & $1.268 \pm 0.651^{\mathrm{A}}$ \\
Older & $60.374 \pm 41.047^{\mathrm{B}}$ & $1.225 \pm 0.802^{\mathrm{B}}$ & $45.740 \pm 38.156^{\mathrm{A}}$ & $0.758 \pm 0.425^{\mathrm{B}}$ \\
\hline
\end{tabular}

Means marked with different letters (A, B) differ statistically highly significant $(\mathrm{p}<0.001)$

Table 4. Means of stress indicators in jumping horses in relation the age in competitive season - September

\begin{tabular}{lcccc}
\hline Stress indicators/age & Heartbeats/min & $\begin{array}{c}\text { Cortisol } \\
(\mathbf{n g} / \mathbf{m l})\end{array}$ & $\begin{array}{c}\text { Glucose } \\
(\mathbf{m g} / \mathbf{d l})\end{array}$ & $\begin{array}{c}\text { Lactate } \\
(\mathbf{m m o l} / \mathbf{l})\end{array}$ \\
\hline Younger & $70.297 \pm 48.121^{\mathrm{A}}$ & $1.107 \pm 0.849^{\mathrm{A}}$ & $52.072 \pm 42.786^{\mathrm{A}}$ & $1.033 \pm 0.519^{\mathrm{A}}$ \\
Older & $59.099 \pm 37.480^{\mathrm{B}}$ & $0.860 \pm 0.687^{\mathrm{B}}$ & $33.180 \pm 23.734^{\mathrm{B}}$ & $0.682 \pm 0.386^{\mathrm{B}}$ \\
\hline
\end{tabular}

Means marked with different letters (A, B) differ statistically highly significant $(\mathrm{p}<0.001)$

\section{DISCUSSION}

Generally, it could be observed that all measured stress indicators were higher in younger compared to older horses during the entire competitive season (May, July and September). The highest value of heartbeats/min was measured at the beginning of the competitive season (May) in younger horses. In consecutive months of the competitive season (July and September), the value of heartbeats/min decreased in both age-class with significantly $(p<0.001)$ higher values determined in younger horses. This is in agreement with other studies (11) which found that the heartbeats/min are always higher in younger horses, both in resting and exercise state. Similar results were also obtained by Ille et al. $(12,13)$ in a study including experienced and unexperienced jumping horses. This is explained by the fact that the heart rate in older horses is uniform and balanced as a result of repetitive training throughout the years.

The determined concentrations of cortisol in horses' saliva were significantly $(\mathrm{p}<0.001)$ higher in younger animals, with the highest concentration in the peak of the competitive season (July). A higher concentration of salivary cortisol implies a more stressful reaction to training in younger horses 
during the peak of the competitive season. The obtained results are in agreement with the findings, where higher plasma cortisol concentrations were found in inexperienced compared to experienced horses $(12,13,14)$. The glucose concentration in saliva was higher in younger horses during the entire competitive season, with significant $(p<0.001)$ differences in May and September. In July, the determined difference in glucose concentration between younger and older horses was high but not statistically significant $(\mathrm{p}>0.05)$. Also, the highest glucose concentration in both age classes was determined in July, while the lowest measured concentration was in the end of the competitive season (September).

Lactate concentration had a similar trend as the cortisol and glucose concentrations. Significantly $(\mathrm{p}<0.001)$ higher concentrations were found in younger animals. The highest values were obtained in the peak of the season (July), regardless of the age. According to Kroner (8), the differences in salivary lactate are indicative of the muscle condition, as well as the body resistance to physical stress during horse training. The lowest values of plasma lactate in experienced horses were also determined by Covalesky et al. (15). Furthermore, many authors $(8,16,17,18)$ describe the lactate concentration as a parameter of horsefitness, which is of significance in equestrian sports. A horse with a lower lactate level is fitter, meaning that the muscle tissue produces less lactic acid which is converted in the blood into the lactate ion. Therefore, König, et al. (5) suggested that the concentration of salivary lactate can be used as an indicator for the evaluation of horse work efficiency.

Horses react individually to stress and can achieve uniform performance with repetitive training. Therefore, older horses have lower values of stress indicators. A similar trend in uniformity in actions achieved by horses through training was reported by other authors $(14,19,20,21,22)$.

\section{CONCLUSION}

Based on obtained results it could be emphasized that all stress indicators (heartbeats, cortisol, glucose, and lactate concentrations), during the entire competitive season, were higher in younger (less experienced) than in older (more experienced) horses. Moreover, all stress indicators, with exception of heartbeats, were highest in the peak of the competitive season (July), while the lowest values of all stress indicators were determined at the end of competitive season (September). Monitoring of stress indicators, especially of heartbeats, could be used for routine evaluation of horse preparedness for a particular activity.

\section{CONFLICTS OF INTEREST}

The authors declared that they have no potential conflict of interest with respect to the authorship and/or publication of this article.

\section{ACKNOWLEDGEMENTS}

The study was supported by the Faculty of Agrobiotechnology Sciences Osijek. We thank all who helped in the field work and in the realization of this paper.

\section{AUTHORS' CONTRIBUTION}

MG was involved in literature review, hypothesis, methodology, data gathering, results and discussion, writing and paper editing. TB did the literature review, data gathering, preparation of data and interpretation of the results. $\mathrm{MB}$ and $\mathrm{GjB}$ reviewed the discussion and the whole paper. VG did the statistical analysis, writing of the paper, discussion and conclusion.

\section{REFERENCES}

1. Mills, D.S., Mc Donnell, S.M. (2005). The domestic horse: the origins, development, and management of its behavior. Cambridge University Press.

2. Hick, C., Hick, A. (2000). Physiology Short Textbook. Urban \& Fischer Verlag, München, 41 - 77, 153 - 160. [in German]

3. Becker-Birck, M., Schmidt, A., Lasarzik, J., Aurich, J., Möstl, E., Aurich, C. (2013). Cortisol release and heart rate variability in sport horses participating in equestrian competitions. Journal of Veterinary Behavior: Clinical Applications and Research 8, 87-90. https://doi.org/10.1016/j.jveb.2012.05.002 PMid: 23380228

4. Snow, D.H., Valberg, S.J. (1994). Muscle anatomy, physiology and adaptations to exercise and training. In: Hodgson D.R. and Rose R.J. (Eds.), The athletic horse (pp. 145-179). WB Saunders Company, Philadelphia, USA.

https://doi.org/10.1016/s0749-0739(17)30749-6 
5. König, V., Borstel, U., Visser, E.K., Hall, C. (2017). Indicators of stress in equitation. Appl Anim Behav Sci. 190, 43-56.

https://doi.org/10.1016/j.applanim.2017.02.018

6. Harbig, S. (2006). Performance monitoring of high performance eventing horses in competition and training: Studies on heart rate. Dissertation. Veterinary University, Hannover [in German]

7. Christensen, J.W., Beekmans, M., van Dalum, M., van Dierendonck, M. (2014). Effects of hyperflexion on acute stress responses in ridden dressage horses. Physiol Behav. 128, 39-45.

https://doi.org/10.1016/j.physbeh.2014.01.024 PMid: 24518858

8. Kroner, K. (2006). Blood and saliva parameters in cold blood horses at rest and during pulling work. Inaugural-Dissertation, München [in German]

9. Strzelec, K., Pietrzak, S., Prochniak, T., Janczarek, I., Cywinska, A., Bereznowski, A. (2020). Salivary cortisol levels in horses and their junior riders during show jumping. Turkish Journal of Veterinary and Animal Sciences 44 (2): 391-395.

https://doi.org/10.3906/vet-1908-17

10. Schmidt, A., Biau, S., Möstl, E., Becker-Birck, M., Morillon, B., Aurich, J., Faure, J.M., Aurich C., (2010). Changes in cortisol release and heart rate variability in sport horses during long-distance road transport. Domest Anim Endocrinol. 38, 179-189. https://doi.org/10.1016/j.domaniend.2009.10.002 PMid: 19962266

11. Klimke, R. (2012). Basic training for riding horses. Franckh Kosmos Verlag 7. [in German]

12. Ille, N., Lewinski, M., Erber, R., Wulf, M., Aurich, J., Möstl, E., Aurich, C. (2013). Effects of the level of experience of horses and their riders on cortisol release, heart rate and heart-rate variability during a jumping course. Universities Federation for Animal Welfare, Animal Welfare, 22, 457-465. https://doi.org/10.7120/09627286.22.4.457

13. Ille, N., Aurich, C., Erber, R., Wulf, M., Palme, R., Aurich, J., Lewinski, M. (2014). Physiological stress responses and horse rider interactions in horses ridden by male and female riders. Comparative Exercise Physiology 10 (2): 131-138. https://doi.org/10.3920/CEP143001
14. Clayton, H. M. (1991). Conditioning sport horses. Saskatoon: Sport Horse Publications.

15. Covalesky, M.E., Russoniello, C.R., Malinowski, K. (1992). Effects of show jumping performance stress on plasma cortisol and lactate concentrations and heart rate and behaviour in horses. J. Equine Vet Sci. 12, 244-251. https://doi.org/10.1016/S0737-0806(06)81454-1

16. Couroucé, A., Chretien, M., Valette, J. P. (2002). Physiological variables measured under field conditions according to age and state of training in French trotters. Equine Vet J. 34, 91-97. https://doi.org/10.2746/042516402776181141 PMid: 10204407

17. Couroucé, A. (1998). Endurance and sprint training. A. Lindner: Conference on Equine Sports. Medicine and Science (pp. 190-202). Wageningen Pers, Wageningen.

18. Munoz, A., Riber, C., Santisteban, R., Lucas, R. G., Castejon, F. M. (2002). Effect of training duration and exercise on blood-borne substrates, plasma lactate and enzyme concentrations in andalusian, anglo- arabian and arabian breeds. Equine Vet J. Suppl 34, 245-251.

https://doi.org/10.1111/j.2042-3306.2002.tb05427.x PMid: 12405695

19. Rose, R. J., Evans, D. L. (1990). Cardiovascular and respiratory function in the athletic horse. In: J.R. Gillespie and N.E. Robinson (Eds.), Equine exercise physiology II (pp. 1-19). ICEEP Publications, Davis, California, USA.

20. Brings, J., Platen, P., Hoffmann, E. (1998). Test method for assessing the endurance and sprint performance in women's handball. Leistungssport 6, 26-31. [in German]

21. Röthing, P., Prohl, R. (2003). Sports Science Lexicon. 7. Auflage, Hoffmann Verlag, Schorndorf. [in German]

22. Voswinkel, L. (2009). Influence of movement activity on growth and endurance parameters in the horse. Institute for Animal Breeding and Animal Husbandry of Agricultural Nutritional Sciences. Faculty of the Cristian Albrechts University in Kiel. [in German] 